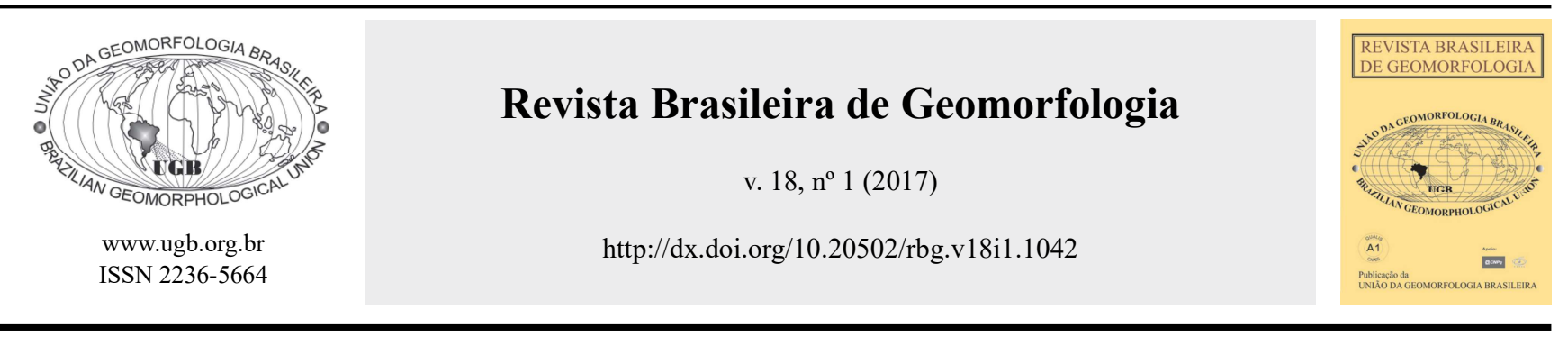

\title{
PROCESSOS FLUVIAIS E MORFOLOGIA EM CONFLUENCIAS DE CANAIS: UMA REVISÃO
}

\section{FLUVIAL PROCESSES AND MORPHOLOGY IN RIVER CHANNEL CONFLUENCES: A REVIEW}

\author{
Vanessa Cristina Dos Santos \\ Instituto de Geociências e Ciências Exatas, Universidade Estadual Paulista \\ Avenida 24 A, $n^{\circ}$ 1515, Rio Claro, São Paulo, CEP: 13.506-900, Brasil \\ Email:vcsgeo@gmail.com \\ José Cândido Stevaux \\ Instituto de Geociências e Ciências Exatas, Universidade Estadual Paulista \\ Avenida 24 A, $n^{\circ}$ 1515, Rio Claro, São Paulo, CEP 13.506-900, Brasil \\ Email: josecstevaux@gmail.com
}

\section{Informações sobre o Artigo}

Recebido (Received):

07/03/2016

Aceito (Accepted):

$30 / 11 / 2016$

Palavras-chave:

Confluência de Canais;

Estrutura do Fluxo; Morfologia,

Transporte de Sedimento.

\section{Keywords:}

River Channel Confluences; Flow Structure; Morphology; Sediment Transport.

\section{Resumo:}

As confluências de canais constituem ambientes com alterações contínuas na estrutura de fluxo e no transporte de sedimentos. São locais na rede de drenagem em que se operam complexas interações entre matéria e energia, proporcionadas pela combinação de fluxos de padrões diferentes. Esta dinâmica peculiar pode influenciar desde aspectos ecológicos até questões de planejamento espacial e de ocupação do espaço. Nas últimas décadas, o interesse científico sobre os processos geomorfológicos ocorridos em confluências de canais tem aumentado. Este interesse deriva da crescente consciência de que os processos fluviais e a morfologia das confluências resumem as características da bacia hidrográfica a montante, ao mesmo tempo em que desempenham importante papel na regulação da circulação da água e sedimentos na rede de drenagem a jusante. Diversos estudos sobre os processos fluviais e morfologia em confluências de canais envolvem experiências laboratoriais, investigação de campo e simulações. Frequentemente estes estudos são uma combinação de diversas disciplinas como geomorfologia, ecologia, engenharia, hidrologia e sedimentologia, evidenciando o caráter multidisciplinar da análise desses ambientes complexos. No Brasil, os estudos sobre os processos geomorfológicos em confluências de canais são poucos, e em sua maioria desenvolvidas em rios de grande porte. Este artigo traz uma revisão e discussão sobre o estado atual do conhecimento sobre confluências de canais. 


\begin{abstract}
:
River channel confluences are sites with continuous changes in the flow structure and sediment transport. A network point of view confluences operate complex interactions between material and energy, provided by the combination of different flow patterns. This particular dynamic can be influential since ecological aspects of management and space occupy planning. In the last decades, scientific interest on geomorphological processes occurring in confluences channels has increased. This interest comes from the growing awareness that processes and morphology of the confluences summarize the characteristics of the upstream watersheds, at the same time they play an important role in the regulation of water and sediments circulating in the downstream river network. Several studies about fluvial processes and morphological at river channel confluences involve laboratory experiments, field research and simulations. Often these studies are a combination of some disciplines such as geomorphology, ecology, engineering, hydrology and sedimentology, evidencing the multidisciplinary character of the analysis of these complex environments. In Brazil, studies about geomorphological processes in river channel confluences are few and mostly developed in large rivers. This paper provides a succinct review and discussion of the current state of knowledge of river channel confluences.
\end{abstract}

\section{Introdução}

As confluências de canais são locais na rede de drenagem em que operam complexas interações entre matéria (água e sedimento) e energia (potência do canal) proporcionadas pela combinação de dois fluxos diferentes. Elas constituem assim, um ambiente com alterações contínuas da estrutura de fluxo (velocidade, direção, descarga) do transporte de sedimentos (carga de fundo e suspensa), como também da morfologia do canal (BEST, 1987 e 1988; BEST e ROY 1991). Além disso, as confluências de canais têm grande valor ecológico intrínseco, em que determinados processos biofísicos particulares e serviços ecossistêmicos são concentrados (RICE et al., 2008b).

Os processos geomorfológicos que ocorrem em confluências de canais têm atraído considerável interesse científico nas últimas décadas. Este interesse deriva da crescente consciência de que os processos fluviais e a morfologia das confluências resumem as características da bacia hidrográfica a montante, ao mesmo tempo em que desempenham importante papel na regulação da circulação da água e sedimentos na rede de drenagem a jusante. As pesquisas sobre confluências de canais abrangem três linhas principais, que são: experiências laboratoriais (MOSLEY, 1976; BEST, 1987, 1988; BEST e ROY, 1991; MCLELLAND et al., 1996; BIRON et al., 1996; LIU et al., 2012; RIBEIRO et al., 2012), investigação em campo (ROY e BERGERON, 1988 e 1990; ASHMORE, 1993; BIRON et al.,1993; BRISTOW et al., 1993; KENWORTHY e RHOADS, 1995; RHOADS e KENWORTHY, 1995, 1998; RHOADS, 1996; DE SERRES et al.,1999;
ASHWORTH et al., 2000; RHOADS e SUKHODOLOV, 2001, 2004; SUKHODOLOV e RHOADS, 2001; RICE et al., 2001; RICE et al., 2006; BOYER et al., 2006; PARSONS et al., 2007; RHOADS et al., 2009) e simulação numérica (WEERAKOON et al., 1991; BRADBROOK et al., 1998; LANE et al., 1999; BRADBROOK et al., 2000, 2001; BIRON et al., 2002; CONSTANTINESCU et al., 2011). Rice et al. (2008a) apresentaram uma revisão da literatura que discute os trabalhos mais significativos em relação à confluência de canais.

Na América do Sul, os estudos sobre os processos geomorfológicos em confluências de canais foram iniciados na década passada. Pesquisadores ingleses e argentinos iniciaram uma pesquisa na confluência do rio Paraná com o rio Paraguai, junto ao Centro de Estudos de Ecologia Aplicada del Litoral (CECOAL) em Corrientes, Argentina (PARSONS et al. 2004). No Brasil, os pesquisadores da Universidade Estadual de Maringá (UEM) voltaram-se para estudo de confluências de pequenos tributários (TURRA et al., 1999) e de grande tributários no alto rio Paraná, rios Paranapanema (PAES, 2007; PAES et al., 2008; STEVAUX et al., 2009b) e Ivaí (BARROS, 2006; FRANCO, 2007; STEVAUX et al., 2009a), todos estes afluentes do rio Paraná. Na região amazônica, as pesquisas sobre confluências são em sua maioria de caráter ecológico (LEITE et al., 2006; DUARTE et al., 2011; RENO e NOVO, 2013). Somente a confluência dos rios Negro e Solimões tiveram suas características morfológicas investigadas (FRANZINELLI, 2011).

Os estudos de confluência abrangem uma ampla gama de tópicos, entre os quais se destacam: geomorfo- 
logia e sedimentologia (MOSLEY, 1976; BEST, 1988), hidráulica e hidrologia (MOSLEY, 1976; BEST, 1987; ROY e BERGERON, 1988), ecologia (PETTS, 1984; BRUNS et al., 1984; PETTS e GREENWOOD, 1985) e a estrutura da rede de drenagem (ABRAHAMS e CAMPBELL, 1976; FLINT, 1980; ABRAHAMS e UPDEGRAPH, 1987). Apesar do grande desenvolvimento dos estudos de confluência, as regiões tropicais ainda carecem de pesquisas. Como exemplo, duas das maiores confluências do planeta, aquelas entre os rios Madeira e Xingu com o rio Amazonas, carecem de estudos relativos aos processos e morfologia.

Este artigo tem intuito de realizar uma revisão e discussão sobre o estado atual do conhecimento sobre confluências de canais quanto ao comportamento do fluxo, morfologia, transporte de sedimentos, bem como a questão da escala de análise das confluências e da rede de drenagem.

\section{O comportamento do fluxo em confluências de canais}

A primeira tentativa para descrever o comportamento do fluxo e para formular um modelo hidráulico para confluências foi realizada por Mosley (1976), e aprimorada por Best (1987). Este último definiu uma modelo com seis zonas de fluxo para as confluências: zona de estagnação do fluxo, zona de deflexão do fluxo, zona de separação de fluxo, zona de máxima velocidade, zona de restabelecimento do fluxo e camadas de cisalhamento (Figura 1).

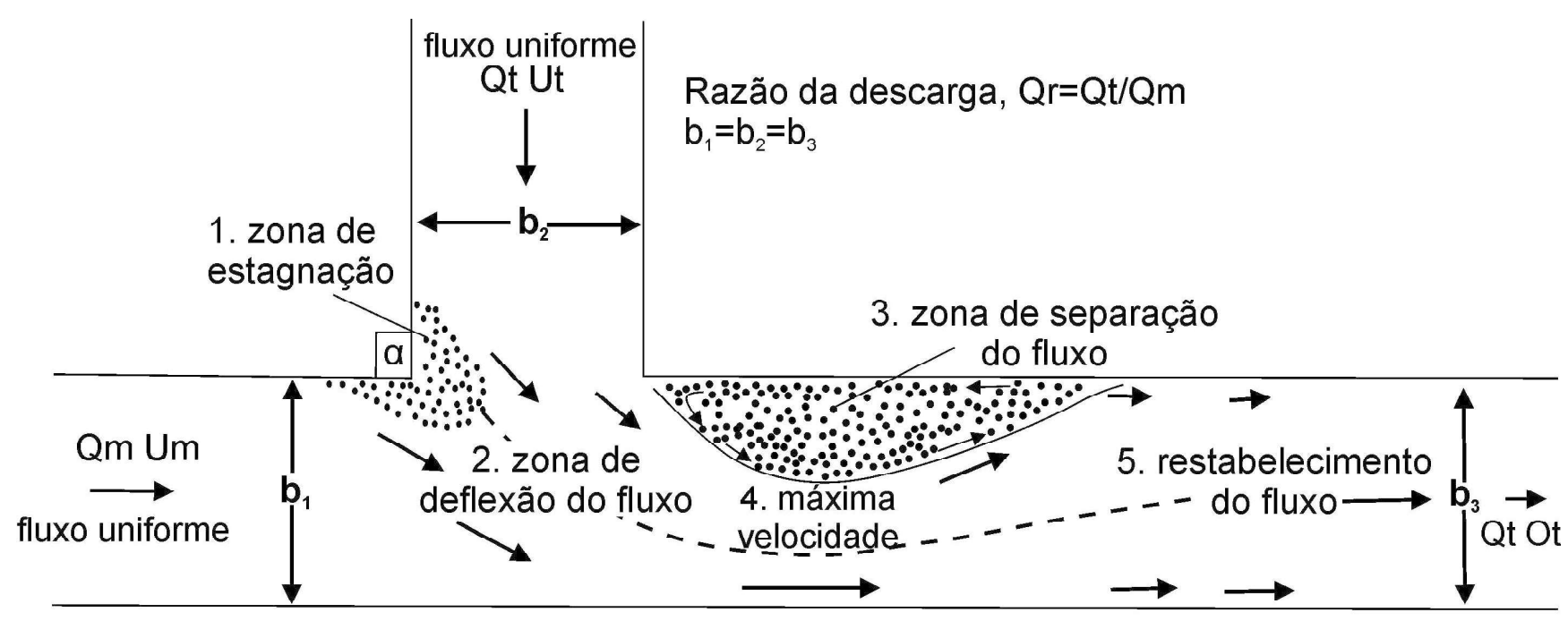

6. - - - - camadas de cisalhamento

Figura 1 - Modelo de dinâmica do fluxo em confluências de canais (Adaptado: BEST, 1987).

Azona de estagnação de fluxo ocorre pela deflexão de ambos os fluxos na junção e está associada primeiramente com um aumento de pressão e da profundidade e em segundo, com uma diminuição da velocidade de fluxo e da tensão de atrito nesta zona (BEST, 1987; BIRON et al., 1996). Azona de separação é criada pela mudança na direção do fluxo, sendo a sua geometria de grande interesse, pois esta influencia na largura do canal pós-confluência, reduzindo a área da seção de fluxo efetiva. Além disso, é uma zona de baixa pressão e recirculação do fluxo, comumente associada com o acúmulo de sedimentos finos. $\mathrm{O}$ aumento das dimensões da zona de separação de fluxo está relacionado ao aumento do ângulo de confluência e à razão de descarga entre o afluente e o canal principal (BEST, 1987; BIRON et al., 1996; WEBER et al., 2001). A zona de máxima velocidade está relacionada à junção dos fluxos, após a zona de separação, sendo esta comumente associada com o aumento da tensão de atrito (BEST, 1987; BIRON e BEST, 1993; BIRON et al., 1996; BOYER et al., 2006). A zona de restabelecimento do fluxo é onde ocorre a recuperação gradual do fluxo (BEST, 1987). As camadas de cisalhamento são formadas ao longo do contato das áreas estagnadas com o fluxo, e esta zona é caracterizada por intensa turbulência, tensão de atrito e uma estrutura de fluxo bem organizada (BEST, 1987; BIRON et al., 1996; RHOADS e SUKHODOLOV, 2001, 2004; SUKHODOLOV e RHOADS, 2001; 
BOYER et al., 2006). Este conjunto de zonas de características distintas foi denominado Zona Hidrodinâmica da Confluência (CHZ) por Kenworthy e Rhoads (1995).

Em um primeiro momento, considerava-se que estas zonas eram controladas pelo ângulo de confluência e a razão da descarga $\left(Q_{r}=Q_{t} / Q_{p}\right.$, em que te $p$ referem-se ao tributário e ao canal principal, respectivamente), no entanto, há outros fatores como a simetria, a razão do momentum $(\mathrm{Mr}=\rho \mathrm{tQtUt} / \rho \mathrm{pQpUp}$, em que p e U são concomitantemente densidade do fluído e velocidade média), a discordância dos leitos, carga transportada (suspensa e/ou sólida), quaisquer diferenças de densidade entre os fluxos de entrada, e entre outros aspectos locais que também afetam estas zonas (BIRON e LANE, 2008).

Há um debate de longa data sobre a natureza e a causa das estruturas de fluxo observadas no modelo formulado por Mosley (1976) e aprimorado por Best

\section{(A)}

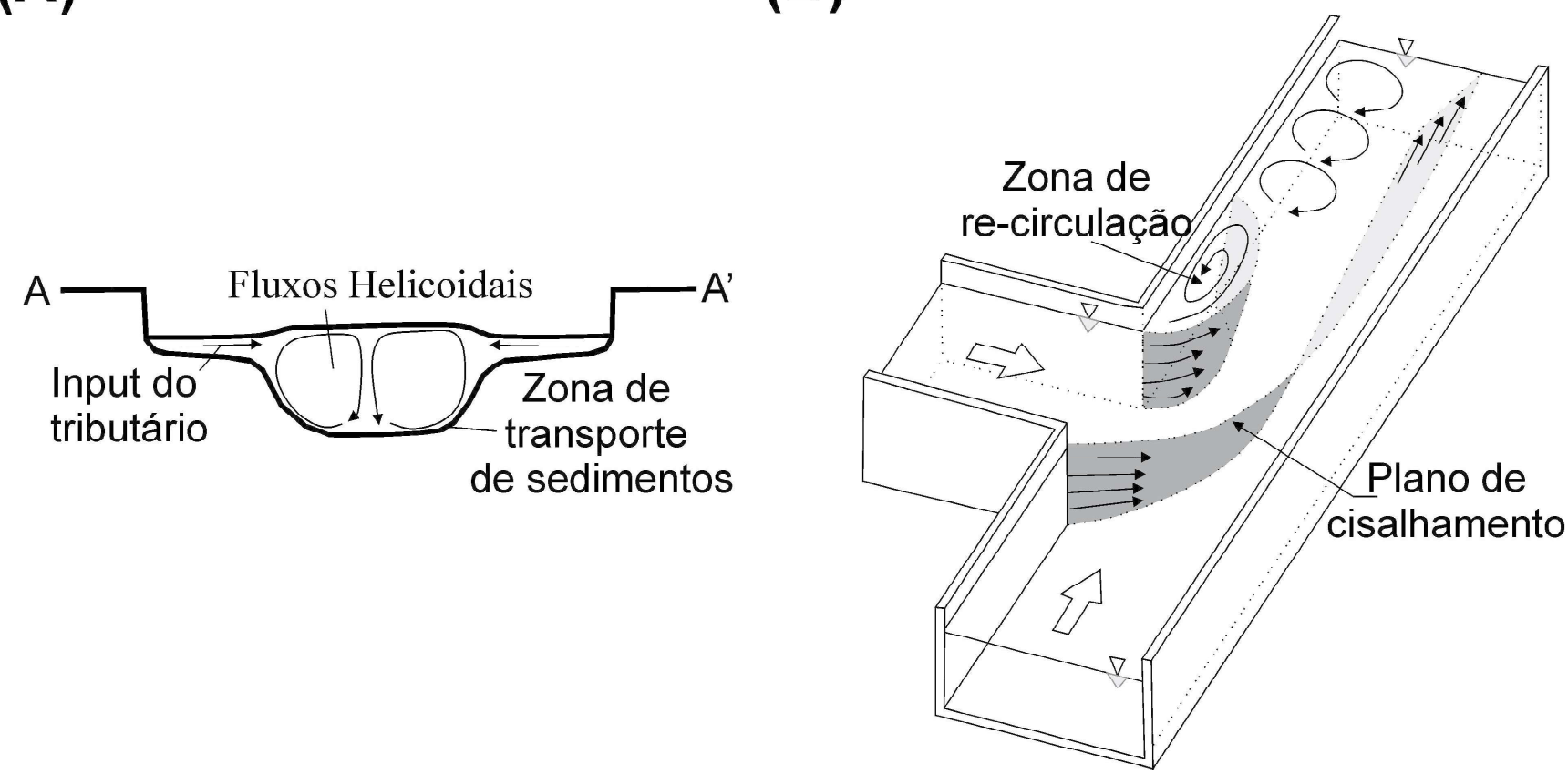

(1987), porém, existe um consenso geral sobre a ocorrência de células rotativas (fluxos helicoidais). Estudos reportam células gêmeas ( $t$ win cells) girando em sentidos opostos (Figura 2-a) ou uma única célula girando no sentido horário (Figura 2-b). A formação destes tipos de fluxo está relacionada principalmente à simetria e à discordância entre leitos (BRADBROOK et al., 2000; BRADBROOK et al., 2001, BIRON et al., 2002). Medições de campo (RHOADS e KENWORTHY, 1995, 1998; RHOADS, 1996) e simulações numéricas (BRADBROOK et al. 2000) sugerem que estes fluxos helicoidais possam evoluir rapidamente para uma única célula, girando no sentido horário e ocupando toda a largura do canal, como resultado da razão angular. Ashmore et al. (1992) e Bridge (1993) sugerem também que estas células sejam responsáveis pela formação de erosões como resultado de uma depressão da zona de máxima velocidade e/ou de cisalhamento intenso do leito nesta região.

Figura 2 - (A) Duas células helicoidais descritas por Mosley (1976). (B) uma única célula no sentido horário descrita por Weber et al., 2001.

Embora existam inúmeras experiências laboratoriais e de investigação em campo, há uma dificuldade em produzir um modelo geral para a estrutura de fluxo das confluências. Segundo Biron e Lane (2008), esta dificuldade não está relacionada aos processos fluviais que conduzem à formação da estrutura de fluxo, mas sim à condições limiares associadas, como: (i) o ângulo e a forma dos canais que se encontrem; (ii) a razão da descarga e razão do momentum; (iii) a discordância entre leitos; e (iv) as eventuais diferenças na densidade do fluxo. Muitas vezes as variações destes parâmetros impedem qualquer comparação de resultados entre estudos e complicam a tarefa de determinar as características dominantes e as variáveis de controle da 
hidráulica confluência.

A simulação numérica tridimensional é uma ferramenta muito importante para melhorar a compreensão sobre a estrutura de fluxo, pois permite uma avaliação mais eficiente do papel das variáveis de controle do que as experiências laboratoriais e as investigações de campo (BIRON e LANE, 2008). Porém, a maioria dos estudos sobre a confluência utilizando simulação numérica tridimensional disponíveis na literatura (como WEERAKOON et al., 1991; BRADBROOK et al., 1998; LANE et al., 1999; BRADBROOK et al., 2000 e 2001, BIRON et al., 2002; CONSTANTINESCU et al., 2011) examinou pequenas junções, sendo escassas as simulações em confluências de grandes rios. Cabe ressaltar que as experiências laboratoriais e as investigações de campo corroboraram com as simulações numéricas no que diz respeito a estrutura do fluxo discutida.

\section{A Morfologia de confluências de canais}

Conforme Best e Rhoads (2008), o conhecimento atual sobre a morfologia de canais de confluências vêm de uma gama de estudos de campo que examinam uma variedade de junções em diferentes escalas, bem como de experiências laboratoriais que detalham a natureza da morfologia dentro de canais fixo e de leitos móveis. Com base nestes estudos foram identificadas cinco características morfológicas principais (MOSLEY, 1976; BEST, 1987, 1988; ASHMORE, 1993; BIRON et al., 1993; RHOADS e KENWORTHY, 1995) em confluências: zona de escavação ("scour hole"), barra de tributário, barra central, barra lateral e região de acumulação (Figura 3). Estas características podem estar presentes ou ausentes em uma confluência e isso depende de vários parâmetros de controle como o ângulo de confluência e a razão da descarga.

\section{Confluência simétrica ' $Y$ '}

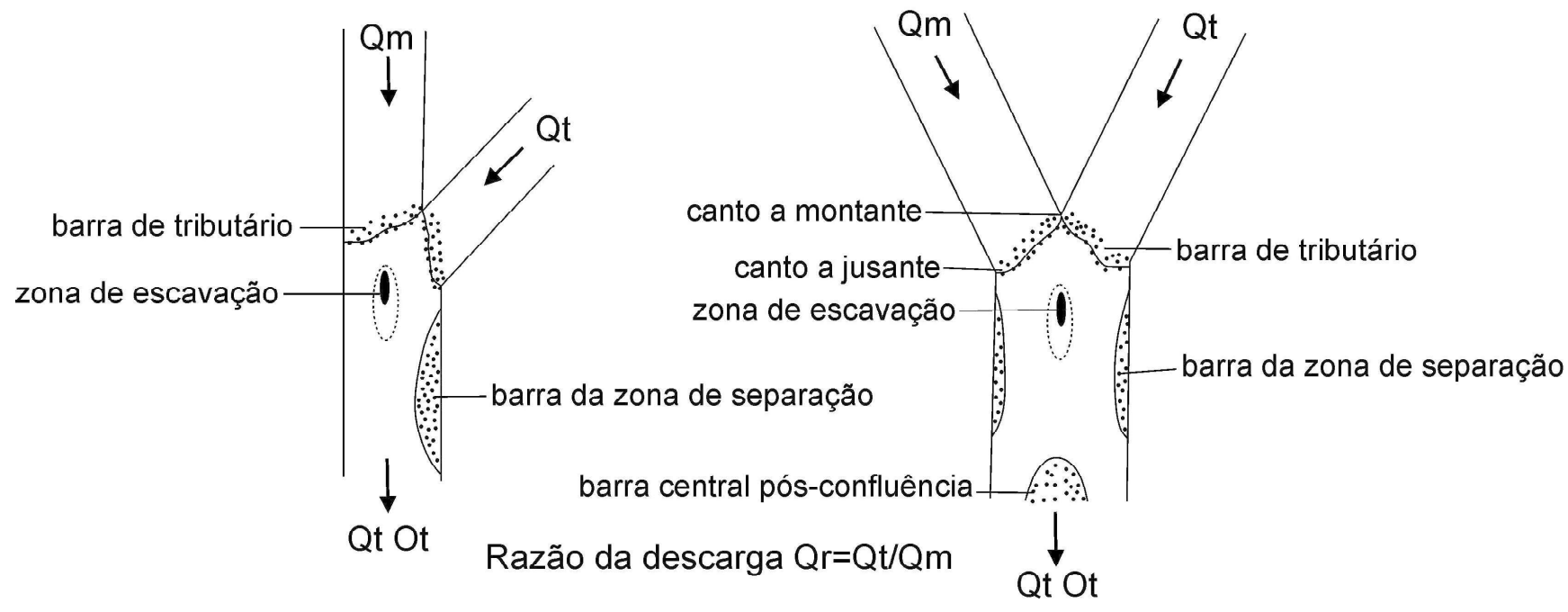

Figura 3 - Modelo das características morfológicas encontradas em confluências assimétricas (y) e simétricas (Y) (Adaptado: Bristow et al., 1993).

Zona da escavação: a zona de escavação é caracterizada por uma depressão no canal receptor originada pela erosão do leito e cuja orientação é bissecta ao ângulo de confluência. Na literatura, há uma gama de trabalhos que são dedicados a documentar a profundidade e a forma da zona de escavação, devido aos efeitos adversos que esta feição causa nas estruturas de engenharia.

Tal zona ocorre desde pequenas confluências de canais retilíneos a grandes confluências de canais entrelaçados, anastomosados e mesmo em canais es- tuarinos (BEST e RHOADS, 2008). Estudos pioneiros demostram que a profundidade da zona de escavação está intimamente relacionada ao ângulo de confluência e a razão da descarga (MOSLEY, 1976; BEST, 1988). Segundo Mosley (1976), a profundidade da zona de escavação tem grande relação com altos ângulos, embora não seja uma relação linear, pois em confluências com ângulos superiores a $100^{\circ}$ esta relação é baixa. Best (1988) averiguou que a uma forte relação entre a profundidade da zona de escavação e a vazão do tributário, quando este é maior que a vazão do canal receptor. 
Entretanto, o estudo de Bryan e Kuhn (2002) em pequenos riachos aponta que o padrão geral da confluência em planta (junction planform) possui maior influência sobre a zona de escavação que o ângulo e a razão da descarga. Ainda segundo os autores supracitados, em confluências simétricas (tipo Y), a zona de escavação é simétrica. Contudo, as confluências assimétricas tendem a ter uma hidrodinâmica complexa, o que leva a uma maior erosão da margem oposta à confluência e também do leito (zona de escavação). Nesse sentido, essa dinâmica seria uma tentativa de a zona da confluência mudar o seu ângulo para se tornar simétrica.

Além disso, confluências com ângulos mais fechados ou que possuem sedimentos que conferem uma alta rugosidade relativa, como sedimentos grossos, podem apresentar também zonas de escavação pouco profundas ou ausentes (Roy et al., 1988). Ademais, a forma do canal receptor, se côncavo ou convexo, também pode influenciar na profundidade da zona de escavação, pois esta conduz a uma estrutura de fluxo diferenciada que promove uma zona de escavação menos profunda do que seria esperado para um determinado ângulo de confluência e uma determinada razão de descarga em um canal receptor retilíneo (ROBERTS, 2004; BEST e RHOADS, 2008).
Nesse sentido, para a formação de uma zona de escavação, o ângulo da confluência e a razão da descarga são parâmetros majoritários. Entretanto, outros aspectos como a forma geral da confluência em planta, a discordância do leito, a rugosidade dos materiais na calha e a posição da confluência no canal podem levar a diferentes hidrodinâmicas e consequentemente afetar as condições erosivas locais, levando a criação de zonas de escavação de diferentes profundidades e morfologias.

Barra de tributário: Diversas confluências possuem acúmulo de sedimento na foz de um ou de ambos os canais (no caso confluências simétricas). Este tipo de acúmulo é denominado barra de tributário (Figura 4b). Este tipo de barra possui uma superfície com mergulho íngreme em direção à zona de escavação. Sua posição e tamanho dependem também do ângulo de confluência e da razão de descarga. Segundo Best e Rhoads (2008), quando o ângulo da confluência é aberto, isso resulta em maior deflexão do fluxo entre os canais e, consequentemente, numa mudança no "caminho" do transporte de sedimentos. Quando o ângulo é fechado, há uma redução da penetração da barra na confluência e há um avanço da barra em direção da zona de escavação e o natural preenchimento desta. No caso em que há discordância entre os leitos, também há ausência ou diminuição destas formas deposicionais.

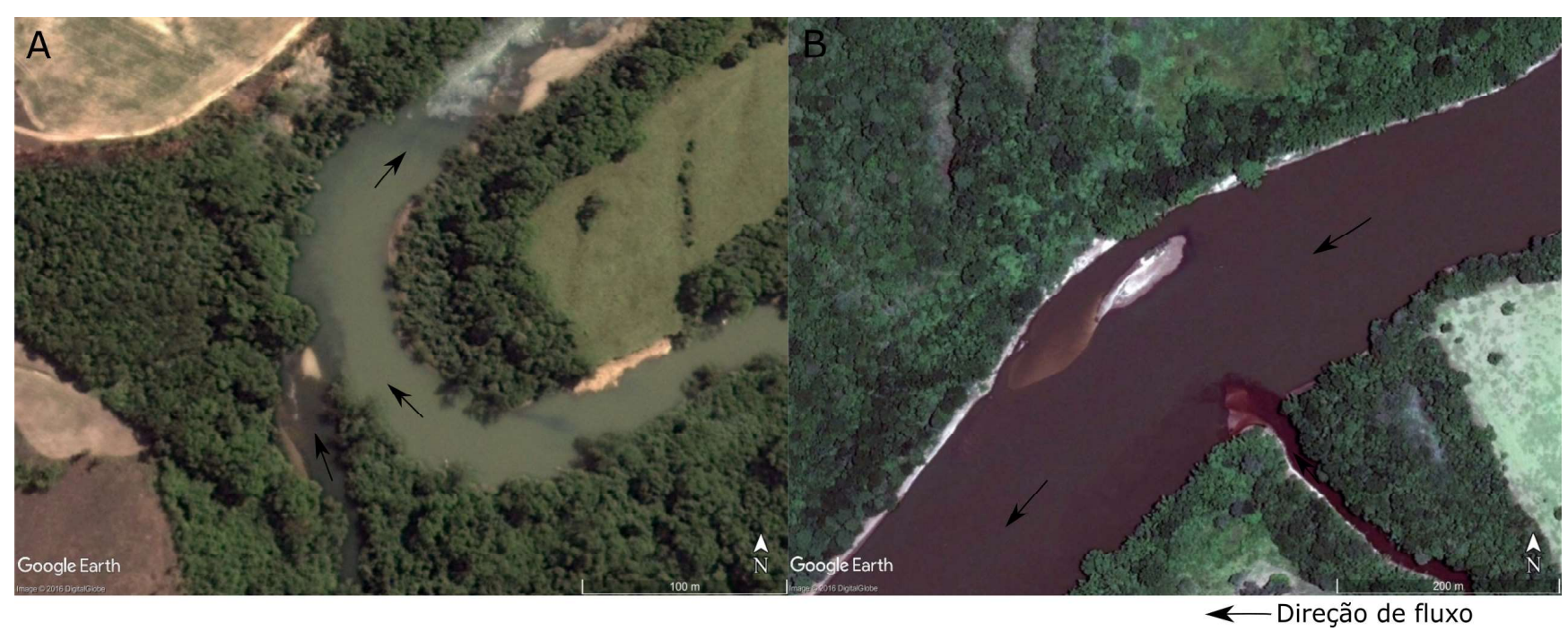

Figura 4 - Exemplos de barras de confluências. (A) barra central; (B) barra de tributário e lateral.

Barra central: Outro tipo de barra encontrada em confluências é a central (Figura 4a). Esta é formada após a zona de escavação e é comumente associada a confluências simétricas de rios entrelaçados (MOSLEY, 1976;
BEST, 1988; ASHMORE, 1993; ASHWORTH et al., 2000). A formação deste tipo de barra está ligada à zona de deflexão do fluxo, onde os sedimentos encaminhados ao redor da zona de escavação acumulam-se depois desta. 
Há também a diminuição da velocidade de fluxo após a zona de escavação, o que favorece a acumulação de sedimentos neste local.

Barra lateral: Rhoads (2006), Best (1988), Turra et al. (1999), Best e Rhoads (2008) e Stevaux et al. (2009a) admitem que a origem das barras laterais está ligada à zona de separação de fluxo (Figura 4b). No entanto, é evidente que estas barras também podem formar-se em regiões onde há desaceleração do fluxo. Segundo Mosher e Martini (2002) e Rhoads (2006), estas barras desenvolvem-se durante eventos de cheia, e uma característica que evidencia este desenvolvimento é a presença de granulometria grossa na superfície, comprovando a migração de formas de leito neste local. Outra característica destas barras, descrita por Rhoads e Kenworthy (1995) e Rhoads (2006), é a formação de uma crista de granulometria fina que marca o limiar da zona de separação de fluxo.

Região de acumulação de sedimento. A região de acumulação de sedimento, localizada no canto da junção, a montante, é caracterizada como uma zona de fluxo lento e de direções inversas. Devido a estas características, os sedimentos encontrados neste local são mais finos do que em outros locais na confluência. Porém, nenhuma forma de barra distinta é reconhecida nesta região (BEST, 1987, 1988; BEST e RHOADS, 2008).

\subsection{Discordância de leito}

A discordância de leito é uma característica das confluências que tem chamado a atenção dos pesquisadores. Esta ocorre quando a profundidade média do leito do tributário difere da profundidade do leito do canal receptor, gerando um degrau. Este degrau não é necessariamente um resultado da dinâmica de fluxo da confluência, mas possui grande influência sobre a mesma. Como exemplo, a discordância pode ser resultante da estrutura geológica local.

No contexto de uma discordância de leito podem ocorrer intensas alterações nos padrões de fluxo, como o aumento na intensidade da turbulência e a ocorrência de ressurgências, que consequentemente interferem na dinâmica sedimentológica e na morfologia local (BIRON et al.,1993; BIRON et al., 1996; BIRON et al., 2004; BOYER et al., 2006).

Boyer et al. (2006) propuseram um modelo conceitual baseado em dados de campo para transporte de sedimentos e mudança morfológica em confluências de leitos discordantes, envolvendo duas condições: a) $\mathrm{M}_{\mathrm{r}}<1$ com débito elevado e; $b) M_{r}>1$ com débito reduzido $\left(\mathrm{M}_{\mathrm{r}}=\right.$ razão do Momentum). Quando $\mathrm{M}_{\mathrm{r}}<1$, existe dominância do fluxo do canal receptor; e quando $\mathrm{M}_{\mathrm{r}}>1$, a dominância é do tributário (Figura 5).

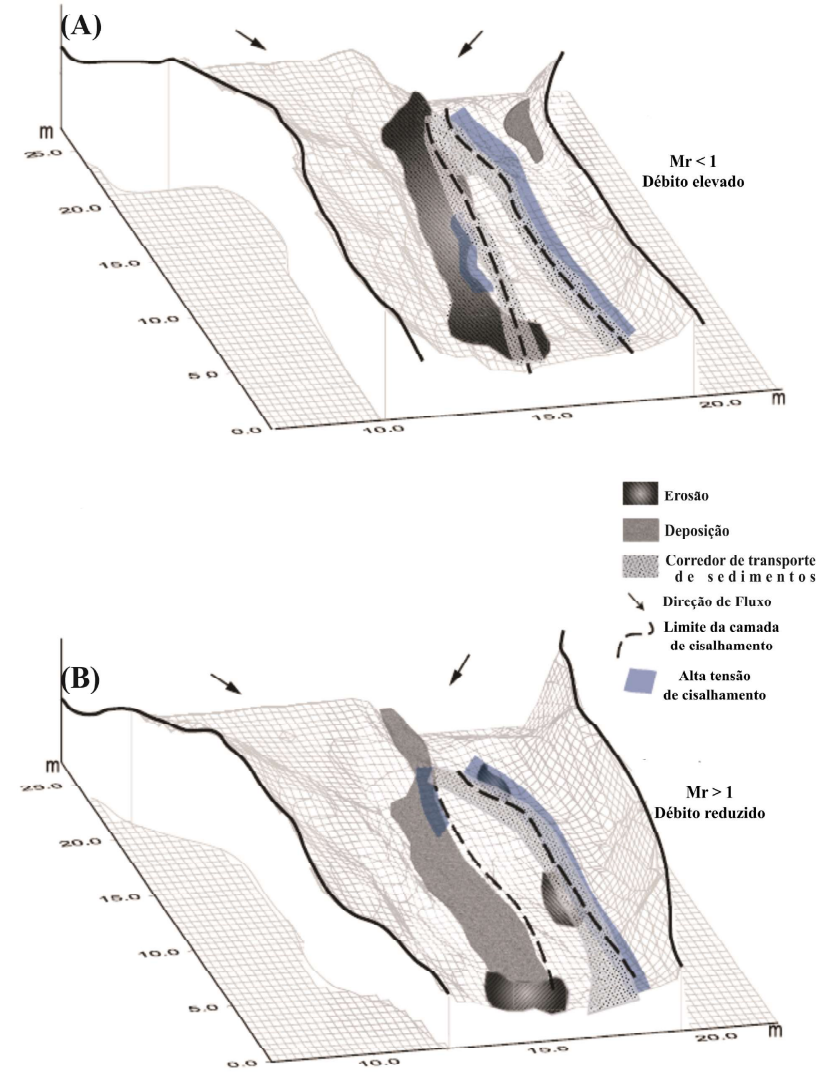

Figura 5 - Modelo conceitual de transporte de sedimentos e morfologia para uma confluência de leito discordante. (A) razão do momentum $<1$ e débito elevado; (B) razão do momentum >1 e débito reduzido (Fonte: BOYER et al., 2006). 
Na condição a), os sedimentos são transportados ao longo de corredores localizados nas bordas das camadas de cisalhamento e as barras laterais são erodidas, resultando num recuo lateral destas. Finalmente, a deposição de sedimentos ocorre de forma esparsa e reduzida na confluência (Figura 5a). Na condição b), os sedimentos transportados seguem o movimento do fluxo vindo do afluente. A deposição de sedimentos ocorre a jusante do vértice da confluência e ao longo da barra lateral, formando zonas de deposição mais extensas que na condição de débito elevado. As zonas de erosão são limitadas e ocorrem na entrada da confluência, no canal principal e a jusante da barra lateral, sendo esta última relacionada ao choque entre as camadas de cisalhamento e a barra (Figura 5b).

Em ambas as condições as camadas de cisalhamentos estão relacionadas a corredores de transporte de sedimento e a alta tensão de cisalhamento. Nesse sentido, a relação entre a zona de camadas de cisalhamento e o transporte de sedimentos confirma o papel da discordância de leito na dinâmica da confluência. A migração desta zona, como resultado da mudança da razão do momentum, modifica as características do fluxo próximo ao leito, das taxas de transporte e da distribuição das zonas de deposição e erosão.

Em outro exemplo da influência da discordância de leito sobre as confluências, Biron et al. (1993) averiguaram que naquelas em que ocorrem grandes discordâncias de leito a zona de escavação central pode ser pequena ou mesmo ausente. Nesses casos, a ausência de zona de escavação estaria ligada a fluxos de natureza distinta, especialmente quando ocorrem fluxos ressurgentes, que é um fenômeno resultante da interação de fluxos e que toma em geral a forma de uma espiral ascendente.

\section{Transporte de sedimentos em confluências de canais}

O transporte de sedimentos, em especial a carga de fundo, serve como ligação entre a estrutura de fluxo e a morfologia de leito, porém na literatura há poucos estudos que se dedicam a entender o transporte de sedimentos em canais de confluências. Sob condições de fluxo constante, tais como os produzidos em experiências laboratoriais, a morfologia evolui para condições de equilíbrio em que a continuidade do fluxo de sedimentos é mantida ao longo da confluência, mantendo assim uma morfologia constante (BEST e RHOADS, 2008). Por outro lado, durante as condições de fluxo transitórios, tais como aqueles que ocorrem em confluências naturais, o leito evolui de forma dinâmica, devido às variações espaciais e temporais na capacidade de transporte.

Mosley (1976) e Best (1988) foram pioneiros no estudo do transporte de sedimentos em confluências de canais. O trabalho experimental de Best (1988) fornece avaliações quantitativas sobre a taxa de transporte em confluências assimétricas e confirma alguns aspectos dos padrões espaciais de transporte de sedimentos observados por Mosley (1976). Nestes estudos foi observado que a maior parte de sedimentos em confluências simétricas se move ao longo dos flancos da zona de escavação (Figura 6), em vez de diretamente através dele, e atribui-se esse padrão à presença de células helicoidais dentro da zona de escavação. Ainda Mosley (1976), demostra que quando há um aumento na carga transportada, e o fluxo e o ângulo são constantes, a profundidade da zona de escavação diminui. Já, os dados de Best (1988), mostram que as cargas de sedimentos de cada tributário são selecionadas dentro da confluência, e que este efeito se torna mais pronunciado à medida que há uma mudança nas direções dos fluxos de entrada e o aumento da profundidade da zona de escavação.

Ashmore (1993) também destaca a influência de pulsos de sedimentos, que podem ser independentes das flutuações de descarga. Neste caso o material é introduzido pela migração de formas de leitos (dunas), que passam pelas confluências de rios entrelaçados alinhados com a zona de escavação, auxiliando na evolução morfológica das confluências ao longo do tempo.

Os trabalhos de Boyer et al. (2006) e Rhoads et al. (2009) trazem novas perspectivas sobre o transporte de sedimentos em confluências. Boyer et al. (2006) examinam a relação entre fluxo, morfologia e transporte de sedimentos em confluência discordantes, e concluíram que a taxa de transporte de sedimentos é alta na borda da zona de cisalhamento (ver item 3.1).

Rhoads et al. (2009), propuseram um modelo baseado em dados investigação de campo ao longo de um período de 15 anos que ilustram a resposta a longo prazo dos padrões espaciais do material de leito e da morfologia sob várias condições hidrológicas (Figura 7). Conforme o modelo, durante os eventos de razão de descarga alta $\left(\mathrm{Q}_{\mathrm{r}}\right)$, os sedimentos penetram na confluência e circundando o canto da junção, produzindo uma assimetria na morfologia, ou seja, tem-se a zona de escavação estreita e ao longo da margem externa da confluência e uma barra de tributário abaixo do canto da junção. Além disso, o material do leito dos canais que compõe a confluência atravessa-a em direções opostas (Figura 7a).

Já em eventos de razão de descarga baixa inicia-se um realinhamento da zona de escavação para o centro da confluência e com significativa erosão da barra de tributário localizada no canto da junção. A carga sedimentar entra segregada em torno da zona de escavação antes de se misturar a jusante (Figura 7b). 


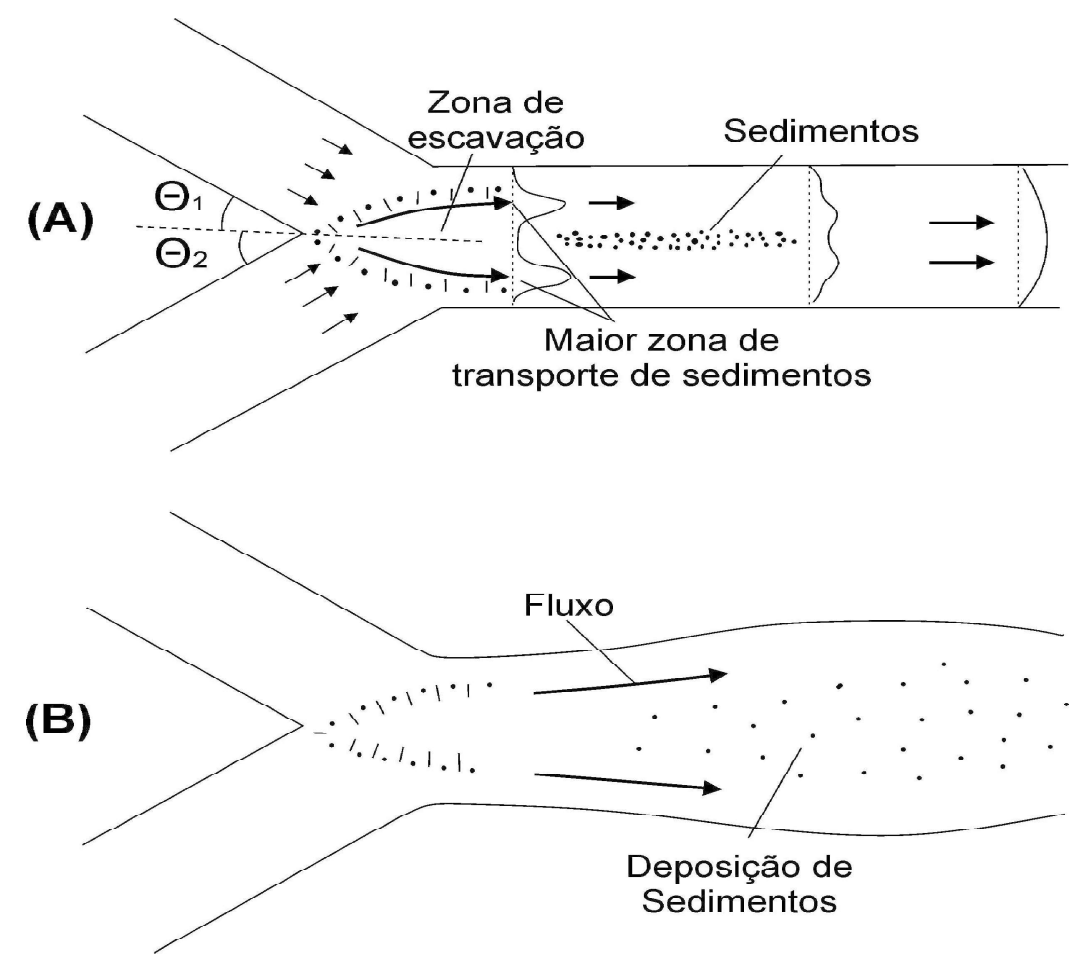

Figura 6 - Modelo dos padrões espaciais do material do leito em confluência canais simétricos (Mosley, 1976). (A) transporte de sedimentos (B); deposição de sedimentos.

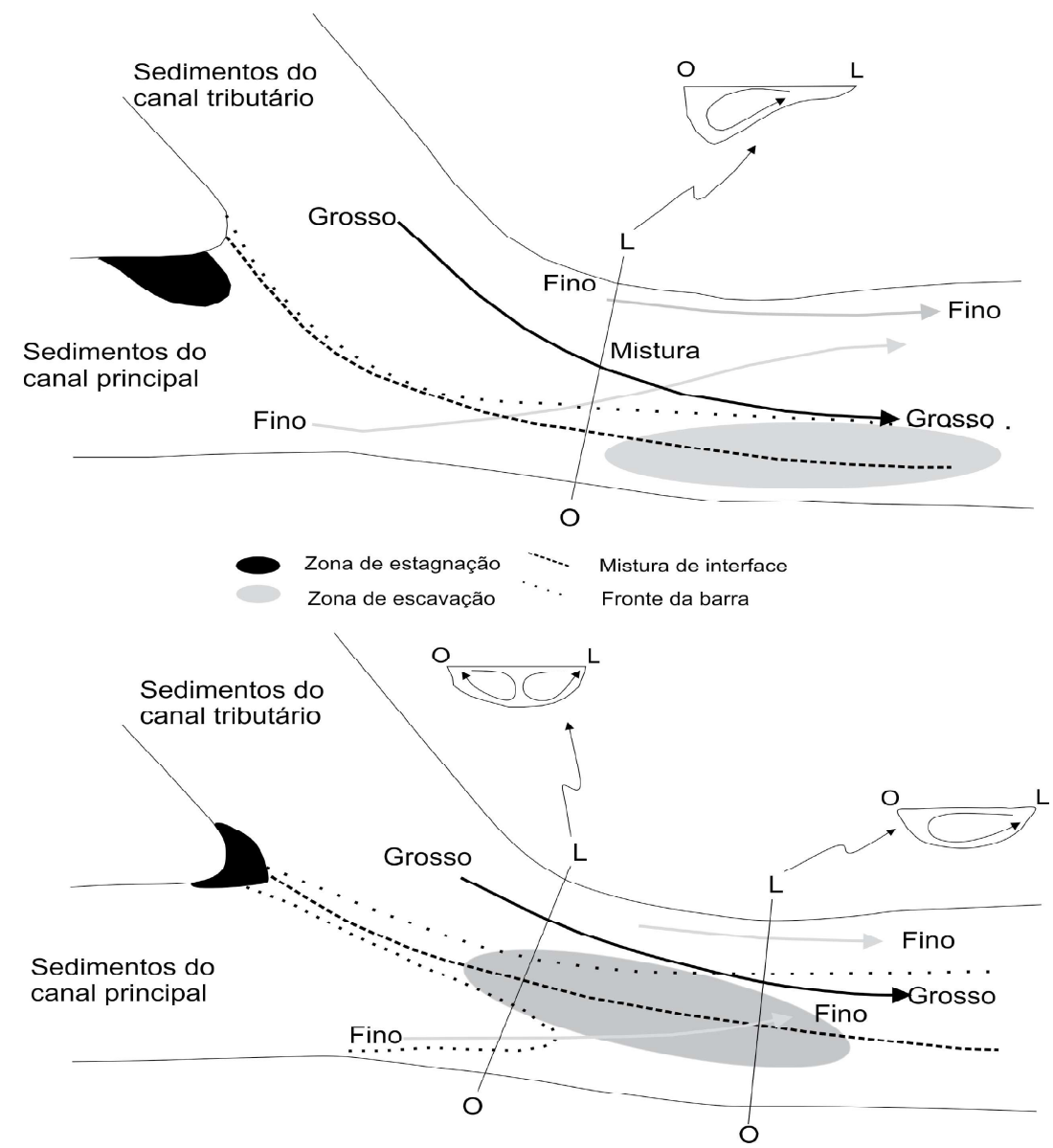

Figura 7 - Modelo conceitual de padrões espaciais do material de leito e da morfologia em confluências de canais assimétricos causada por (A) razão da descarga alta; (B) razão da descarga baixa (Fonte: RHOADS et al., 2009). 


\section{Confluências de Canais de Grandes Rios - Casos Especiais}

A grande maioria dos estudos sobre confluência de canais recorrentes na literatura foram realizados em canais pequeno porte. Embora estes estudos permitam a identificação das principais variáveis que controlam a hidráulica e a morfologia das confluências, este conhecimento não se aplica totalmente às confluências de grandes rios.

Estes drenam áreas significativamente diferentes em termos geológicos e climáticos (PERSONS et al., 2004; PERSONS et al., 2008) e a relação das principais variáveis hidráulicas definidas para rios médios, como declividade versus descarga de margens plenas (LEOPOLD e WOLMAN, 1957), potência de canal versus diâmetro da partícula (VAN DEN BERGER, 1995) e declividade versus razão largura/profundidade (PARKER, 1976), não se aplicam a mega rios com vazão superior a $17.000 \mathrm{~m}^{3} \mathrm{~s}^{-1}$ (LATRUBESSE, 2008).

Dessa forma, compreender a influência dos efeitos de escala sobre os processos fluviais de grandes confluências é vital, pois nestes locais há passagem de volumes significativos de água e sedimentos que causam impactos não somente na escala local, mas também regional (PARSONS et al., 2004).

Com o advento e a popularização do perfilador Doppler de corrente (ADCP) e da sonda acústica georreferenciada, houve uma simplificação nos estudos de confluências em grandes rios. Estes instrumentos permitem uma cartografia rápida e exata do fluxo e da morfologia do leito (RICHARDSON e THORNE, 2001; MCLELLAND et al., 1999; ASHWORTH et al., 2000; PARSONS et al., 2004, 2005, 2007; STEVAUX et al., 2009a). A maior parte dos trabalhos sobre grandes confluências compara a morfologia e estrutura do fluxo destes modelos desenvolvidos para junções menores, permitindo a discussão sobre a influência de processos fluviais sobre a dinâmica da mistura de fluidos em grandes confluências.

Best e Ashworth (1997) avaliaram a morfologia da confluência dos rios Jamuna e Ganges e constataram que a morfologia desta é similar às de confluências de pequena escala apresentando zona de escavação, barras laterais e uma região de acumulação. Apesar da grande profundidade da zona de escavação desta confluência, não foi averiguada a formação de um mergulho íngreme na transição entre as barras de tributários e a zona de escavação, característica observada em confluências de pequeno porte, mas apenas a ocorrência se dunas pequenas migrando.

A ausência de mergulho íngreme demostra o papel da zona hidrodinâmica da confluência, em específico, a zona máxima de velocidade do fluxo e zona de camadas de cisalhamento, que geraram a zona erosiva central, ao invés de criar uma morfologia íngreme ou de barra de tributário. Semelhante situação foi verificada por Parsons et al. (2007) na confluência dos rios Paraná e Paraguai na Argentina, por Stevaux et al. (2009a) na confluência dos rios Ivaí e Paranapanema com o rio Paraná e por Franzinelli (2011) para a confluência dos rios Negro com o Solimões no Brasil.

Os trabalhos supracitados sugerem que mergulhos íngremes na transição entre barras de tributários e a zona de escavação são raras em confluências de grandes rios, embora as zonas erosivas possam apresentar grandes profundidades. Outro aspecto é a presença de dunas e barras que retrabalham grande quantidade de sedimentos de fundo, tendo impacto significativo na dinâmica de fluxo, como modificação da estrutura de fluxo verificado por Parsons et al. (2007).

\section{Confluência de Canais no Contexto da Rede de Drenagem}

À medida em que os tributários adicionam vazão e sedimentos nos canais receptores, são observadas modificações tanto no contexto da confluência como também por certa distância a jusante e a montante do canal principal.

Contudo, dentro de uma rede de drenagem há vários fatores que determinam as características das confluências, incluindo a diferença de tamanho entre os dois canais, a erosão e transporte de sedimentos, as características das bacias tributárias (forma, densidade de drenagem, entre outras), a granulometria da carga sedimentar adicionada, a idade dos depósitos, a geometria do vale e dos canais e distúrbios estocásticos (incêndios, tempestades, inundações, entre outros) (Tab. 1). Estes fatores podem variar ou ter intensidades distintas dentro de uma mesma rede de drenagem, ocasionando confluências com características distintas (BENDA, 2008). 
Tabela 1: Fatores determinantes do ambiente de confluência

\begin{tabular}{|c|c|}
\hline Natureza & Fatores (exemplos) \\
\hline Magnitude dos canais & Área da bacia, vazão, entre outros \\
\hline Carga transportada & Carga suspensa (Qs), carga de fundo (Qf e textura) e granulometria \\
\hline Funcionamento & Regime de descarga (líquida e sólida). \\
\hline Geometria & Vale, padrão de canal, ângulo de confluência, entre outros \\
\hline Erosão & Margens e calha \\
\hline História & $\begin{array}{l}\text { Eventos estocásticos (mega inundações, incêndios na bacia, terremotos, } \\
\text { etc.) e idade dos depósitos }\end{array}$ \\
\hline
\end{tabular}

De acordo com Rice et al. (2008a) há poucos estudos que relacionam a interação entre o canal principal e seus afluentes, principalmente no que se refere aos afluentes muito pequenos ou com hidrogramas assíncronos (difícil identificação de um padrão temporal). Benda et al. (2004) avaliaram a relação entre a geometria da rede drenagem, processos fluviais e a morfologia que ocorrem em junções de canais utilizando os dados de 14 estudos realizados no Oeste do Estados Unidos da América e no Canadá, perfazendo 167 confluências ao longo $730 \mathrm{~km}$ de canais, abrangendo 7 ordens de magnitude em dois tipos de clima (úmido e semiárido), incluindo rios regulados e não regulados (isto é, controlados por barramentos).

Os autores concluíram que a probabilidade de um canal tributário afetar a morfologia local do canal principal está diretamente ligada a proporção entre a área de drenagem dos canais. Porém há outros fatores importantes como a forma de bacia, a geometria da rede (incluindo a densidade de drenagem) e as leis do dimensionamento do fluxo que influenciam na probabilidade do canal tributário afetar ou não o canal principal (BENDA, 2008).

Nesta mesma abordagem, Dos Santos (2015) avaliou 58 confluências da bacia hidrográfica do rio Ivaí (Estado do Paraná), uma bacia de médio porte (área de $38.000 \mathrm{~km}^{2}$ ), dos quais dois terços são de fundo rochoso e um terço de fundo misto. Nesse trabalho foram analisados os aspectos geomorfológicos e hidrossedimentares das confluências de acordo com a influência dos fatores locais e regionais. Foi observado que, apesar da heterogeneidade das propriedades fisiográficas desta bacia, a estruturação geológica (fraturas, falhas e lineamentos) é o principal fator de controle da configuração das confluências. Este fator se reflete proeminentemente nos aspectos da rede de drenagem e, consequentemente, na dinâmica hidrossedimentológica e morfológica local das confluências.

\section{Considerações Finais}

Nas últimas décadas, com desenvolvimento de instrumentação avançada e de novos modelos experimentais, a pesquisa sobre confluências de canais evoluiu rapidamente. Esta evolução se iniciou com o trabalho pioneiro de Mosley publicado em 1976, com experimentos em laboratório. Este trabalho abriu o caminho para a identificação das principais variáveis que controlam estruturas de fluxo e morfologia associada às confluências de canais: o ângulo de confluência e a sua simetria, razão do momentum $\left(\mathrm{M}_{\mathrm{r}}\right)$, razão da descarga $\left(Q_{r}\right)$ e a discordância entre canais.

Essas variáveis levam a diversos tipos de estruturas de fluxo, porém, as investigações em confluências têm documentado a existência de algumas características comuns: estagnação de fluxo, deflexão do fluxo (quando os tributários adentram a confluência), separação de fluxo, zona de máxima velocidade, restabelecimento do fluxo a jusante da zona de separação e as camadas de cisalhamento, associadas à fluxos ressurgentes.

A morfologia dos canais na confluência, no entanto, reflete a estrutura de fluxo e algumas características comuns também podem ser identificadas, tais como: a zona de escavação - originada pela turbulência dos fluxos que se encontram, as barras de tributário - que se formam na foz dos contribuintes, as barras centrais - formadas após a confluência, as barras laterais - que são associadas às zonas de separação do fluxo ou de deflexão do fluxo e a região de acumulação de sedimentos - situada no canto da confluência, a montante e associada à zona de estagnação do fluxo. A discordância do leito também é uma forma que, embora nem sempre 
seja resultante direta da dinâmica dos fluxos, possui forte influência na formação de outras características morfológicas.

Este conjunto de características comuns identificadas tanto para a estrutura do fluxo quanto para a morfologia dá uma ideia da complexidade da dinâmica de uma confluência na escala local. Porém, é crucial a ampliação do conhecimento dos processos fluviais para a escala da rede de drenagem. Existe uma consciência crescente nas ciências do sistema fluvial que é necessário uma melhor integração dos conhecimentos dos processos fluviais em toda uma gama de escalas espaciais. A compreensão do funcionamento das junções numa rede de drenagem pode subsidiar o desenvolvimento modelos e ferramentas importantes para o planejamento e a conservação do meio ambiente.

\section{Referências Bibliográficas}

ABRAHAMS, A. D.; CAMPBELL, R. N. Source and tributarysource link lengths in natural channel networks. Geological Society of America Bulletin, v. 87, p. 1016-1020, 1976.

ABRAHAMS A. D, UPDEGRAPH J. Some space-filling controls on the arrangement of tributaries in dendritic channel networks. Water Resources Research, v. 23, p. 489-495, 1987.

ASHMORE, P. E. Anabranch confluence kinetics and sedimentation processes in gravel-braided streams. In: BEST, J. L.; BRISTOW, C. S. Braided Rivers. v. 75, 1993. p. 129-146.

ASHMORE, P. E.; FERGUSON, R. I.; PRESTEGAARD, K.L.; ASHWORTH, P. J.; PAOLA, C. Secondary flow in coarse grained braided river confluences. Earth Surface Processes and Landforms, v. 17, p. 299-312, 1992.

ASHWORTH P. E.; BEST, J. L.; RODEN, J.; BRISTOW, C.; KLAASSEN, G. Morphological evolution and dynamics of a large, sand braid-bar, Jamuna River, Bangladesh. Sedimentology, v. 47, p. 533-555, 2000.

BARROS, C. S. Dinâmica Sedimentar e Hidrológica na Confluência do Rio Ivaí com o Rio Paraná, Município de Icaraíma - PR. 2006. 69 f. Dissertação (Mestrado em Geografia) - Centro de Ciências Humanas, Letras e Artes, Universidade Estadual de Maringá, Maringá, 2006.

BENDA, L. Confluence environments at the scale of river networks. In: RICE, S.P.; ROY, A. G.; RHOADS, B. L. River confluences, tributaries and the fluvial network. v. 1, 2008. cap. 13 , p. 271-300.
BENDA, L.; ANDRAS, K.; MILlER, D.; BIGELOW, P. Confluence effects in rivers: Interactions of basin scale, network geometry, and disturbance regimes. Water Resources Research, v. 40, W05402, DOI: 10.1029/2003WR002583, 2004.

BEST, J. L. Sediment transport and bed morphology at river channel confluences. Sedimentology, v. 35, p. 481-498, 1988.

BEST, J. L. Flow dynamics at river channel confluences: Implications for sediment transport and bed morphology. In: ETHERIDGE, F. G.; FLORES, R. M.; HARVEY, M. D. Recent Developments in Fluvial Sedimentology. v. 39, 1987. p. 27-35.

BEST, J. L.; RHOADS, B. L. Sediment transport, bed morphology and the sedimentology of river channel confluences. In: RICE, S. P.; ROY, A. G.; RHOADS, B. L. River confluences, tributaries and the fluvial network. v. 1, 2008. cap. 4, p. 45-72.

BEST, J. L.; ASHWORTH, P. Scour in large braided rivers and the recognition of sequence stratigraphic boundaries. Nature, v. 387 , p. $275-277,1997$

BEST, J. L.; ROY, A. G. Mixing-layer distortion at the confluence of channels of different depth. Nature, v. 350, p. 411-413, 1991.

BIRON, P. M.; LANE, S. N. Modelling hydraulics and sediment transport at river confluences. In: RICE, S. P.; ROY, A. G.; RHOADS, B. L. River confluences, tributaries and the fluvial network. v. 1, 2008. cap. 3, p. 17-43.

BIRON P.; BEST, J. L.; ROY, A. G. Effects of bed discordance on flow dynamics at open channel confluences. Journal of Hydraulic Engineering, v. 122, p. 676-682, 1996.

BIRON, P.; DE SERRES B.; ROY, A. G.; BEST, J. L. Shear layer turbulence at an unequal depth channel confluence. In: CLIFFORD, N. J.; FRENCH, J. R.; HARDISTY, J. Turbulence: Perspectives on Flow and Sediment Transport. 1993. p. 197-213.

BOYER, C.; ROY, A. G.; BEST, J. L. Dynamics of a river channel confluence with discordant beds: Flow turbulence bed load sediment transport and bed morphology. Journal of Geophysical Research - Earth Surface, v. 111, F04007, DOI:10.1029/2005JF000458, 2006.

BRADBROOK, K. F.; LANE, S. N.; RICHARDS, K. S.; BIRON, P. M.; ROY, A. G. Role of bed discordance at asymmetrical river confluences. Journal of Hydraulic Engineering, v. 127, p. 351-368, 2001

BRADBROOK, K. F.; LANE, S. N.; RICHARDS, K. S. Numerical simulation of three-dimensional time-averaged flow structure at river channel confluences. Water Resources Research, v. 36, p. 2731-2746, 2000. 
BRADBROOK, K. F.; BIRON, P. M.; LANE, S. N.; RICHARDS, K. S.; ROY, A. G. Investigation of controls on secondary circulation in a simple confluence geometry using a threedimensional numerical model. Hydrological Processes, v. 12, p. 1371-1396, 1998.

BRIDGE, J. The interaction between channel geometry water flow sediment transport and deposition in braided rivers. In: BEST, J. L.; BRISTOW, C. S. Braided Rivers. v. 75, 1993. p. 13-72.

BRISTOW, C. S.; BEST, J. L.; ROY, A. G. Morphology and facies models of channel confluences. In: MARZO. M.; PUIGDEFABREGAS. C. Alluvial Sedimentation. v. 17, 1993. p. $91-100$.

BRUNS, D. A.; MINSHALL, G. W.; CUSHING, C. E.; CUMMINS, K. W.; BROCK, J. T.; VANNOTE, R. L. Tributaries as modifiers of the river continuum concept: Analysis by polar ordination and regression models. Archive Hydrobiologie, v. 99, p. 208-220, 1984.

BRYAN, R. B.; KUHN, N. J. Hydraulic conditions in experimental rill confluences and scour in erodible soils. Water Resources Research, v. 38, n. 5, DOI: 10.1029/2000WR000140, 2002.

CONSTANTINESCU, G.; MIYAWAKI, S.; RHOADS, B.; SUKHODOLOV, A.; KIRKIL, G. Structure of turbulent flow at a river confluence with momentum and velocity ratios close to 1: Insight provided by an eddy-resolving numerical simulation. Water Resources Research, v. 47, W05507, DOI:10.1029/2010WR010018, 2011.

DE SERRES B.; ROY, A. G.; BIRON, P. M.; BEST, J. L. Threedimensional structure of flow at a confluence of river channels with discordant beds. Geomorphology, v. 26, p. 313-335, 1999.

DOS SANTOS, V.C. Ambientes de confluência no contexto da rede de drenagem: Exemplo da bacia hidrográfica do rio Ivaí - Estado do Paraná. 2015. 458p. Tese (Doutorado em Geociências e Meio Ambiente). Instituto de Geociências e Ciências Exatas, Universidade Estadual Paulista, Rio Claro. 2015.

DUARTE, C.; SOUZA, V. S.; NUNES, C. O. Variação nictemeral na composição da ictiofauna no lago Catalão (confluência dos rios Solimões e Negro). Amazon Science, v. 1, n. 1, p. 18-27, 2012.

FLINT J. J. Tributary Arrangements in Fluvial Systems. American Journal of Science. v. 280, p. 26-45, 1980.

FRANCO, A. L. A. Análise da Dinâmica do Fluxo e da
Morfologia na Confluência dos Rios Ivaí e Paraná, PR/ MS. 2007. 98 f. Dissertação (Mestrado em Análise Ambiental). Universidade de Guarulhos, Guarulhos. 2007.

FRANZINELLI, L. Características morfológicas da confluência dos rios Negro e Solimões (Amazonas, Brasil). Revista Brasileira de Geociências, v. 41, n. 4, p.5 87-596, 2011.

KENWORTHY S. T.; RHOADS, B. L. Hydrologic control of spatial patterns of suspended sediment concentration at a small stream confluence. Journal of Hydrology, v. 168, p. 251-63, 1995.

LANE, S. N.; BRADBROOK, K. F.; RICHARDS, K. S.; EL-HAMES, A.; BIRON, P. M.; ROY, A.G. The application of computational fluid dynamics to natural river channels: Three-dimensional versus two-dimensional approaches. Geomorphology, v. 29, p. 1-20, 1999.

LATRUBESSE, E. M. Patterns of anabranching channels: The ultimate end member adjustment of mega rivers. Geomorphology, v. 101, p. 130-145, 2008.

LEITE, R. G.; SILVA, J. V. V.; FREITAS, C. E. Abundância e distribuição das larvas de peixes no Lago Catalão e no encontro dos rios Solimões e Negro, Amazonas, Brasil. Acta Amazonica, v. 36, n. 4, p. 557-562, 2006.

LEOPOLD, L. B.; WOLMAN, M. G. River channel patterns - braided, meandering, and straight. U. S. Geological Survey Professional Paper, v. 282, n. B, p. 39-85, 1957.

LIU, T.; Li CHEN, L.; FAN, B. Experimental study on flow pattern and sediment transportation at a $90^{\circ}$ open-channel confluence. International Journal of Sediment Research, v. 27, n. 2, p. 178-187, 2012.

MCLELLAND, S. J.; ASHWORTH, P. J.; BEST, J. L. Flow structure and transport of sand-grade suspended sediment around an evolving braid bar, Jamuna River, Bangladesh. In: SMITH, N. D.; ROGERS, J. Fluvial Sedimentology. v. 28, 1999. p. 43-57.

MCLELLAND, S. J.; ASHWORTH, P. J.; BEST, J. L. The origin and downstream development of coherent flow structures at channel junctions. In: ASHWORTH, P. J.; BENNETT, S. J.; BEST, J. L.; MCLELLAND, S. J. Coherent Flow Structures in Open Channels. 1996. p.459-490.

MOSHER, S. J.; MARTINI, I. P. Coarse grained flood bars formed at the confluence of two subartic rivers affected by hydroelectric dams, Ontario, Canada. In: MARTINI, P. I.; BAKER, V. R.; GARZON, G. Flood and Megaflood Processes and Deposits: Recent and Ancient Examples. v. 31, 2002. p. 213-231. 
MOSLEY, M. P. An experimental study of channel confluences. Journal of Geology. v. 84, p. 535-562, 1976.

PAES, R. Análise da dinâmica do fluxo na confluência dos rios Paraná e Paranapanema. 2007. 53 f. Dissertação (Mestrado em Análise Ambiental). Universidade de Guarulhos, Guarulhos, 2007.

PAES, R.; STEVAUX, J. C.; ETCHEBEHERE, M. L. C.; LELI, I. T. Dinâmica e morfologia do canal de confluência dos rios Paraná e Paranapanema pelo método do mapeamento temporal. Geografia, Londrina, v. 17, p. 37-47, 2008.

PARKER, G. On the cause and characteristic scales of meandering and braiding in rivers. Journal of Fluid Mechanics, v. 76, p. 457-480, 1976.

PARSONS, D. R.; BEST, J. L.; LANE, S. N.; KOSTASCHUK, R. A.; HARDY, R. J.; ORFEO, O.; AMSLER, M. L.; SZUPIANY, R. N. Large river channel confluences. In: RICE, S. P.; ROY, A. G.; RHOADS, B. L. River confluences, tributaries and the fluvial network. v. 1, 2008. cap. 5, p. 74-118.

PARSONS, D. R.; BEST, J. L.; LANE, S. N.; ORFEO, O.; HARDY, R. J.; KOSTASCHUK, R. Form roughness and the absence of secondary flow in a large confluence difference, Río Parana, Argentina. Earth Surface Processes and Landforms, v. 32, p. 155-162, 2007.

PARSONS, D. R.; BEST, J. L.; ORFEO, O.; HARDY, R. J.; KOSTASCHUK, R. LANE, S. N. Morphology and flow fields of three-dimensional dunes, Río Paraná, Argentina: Results from simultaneous multibeam echo sounding and acoustic Doppler current profiling. Journal of Geophysical Research, v. 110, F04S03. DOI: 10.1029/2004JF000231, 2005.

PARSONS, D. R.; BEST, J. L.; LANE, S. N; HARDY, R. J; ORFEO, O.; KOSTASCHUK, R. The Morphology, 3D flow structure and sediment dynamics of a large river confluence: The Río Paraná and Río Paraguay, NE Argentina. In: GRECO, M.; CARRAVETTA, A.; DELlamORTE, R. River flow. Proceedings of the Second International Conference on Fluvial Hydraulics, Napoli, Italy, v. 1, 2004, p. 43-48.

PETTS, G. E. Impounded Rivers: Perspectives for Ecological Management. Chichester, United Kingdom: John Wiley and Sons, 1984. $326 \mathrm{p}$.

PETTS G. E.; GREENWOOD M. Channel changes and invertebrate faunas below Nant-y-Moch dam, River Rheidol,Wales, UK. Hydrobiologia, v. 122, p. 65-80, 1985.

RENO, V. F.; NOVO, E. M. L. M. 2013 Alterações da paisagem de várzea do Baixo Amazonas entre 1970 e 2008. In: Anais XVI
Simpósio Brasileiro de Sensoriamento Remoto. Anais ... Foz do Iguaçu - Paraná, 2013, p. 7778-7785.

RHOADS, B. L.; RILEY, J. D.; MAYER, D. R. Response of bed morphology and bed material texture to hydrological conditions at an asymmetrical stream confluence. Geomorphology, v.109, p.161-173, 2009.

RHOADS, B. L. Scaling of confluence dynamics in river systems: Some general considerations. In: PARKER, G.; GARCÍA, M. H. River, Coastal and Estuarine Morphodynamics. 2006. p. 379-387.

RHOADS, B. L.; SUKHODOLOV, A. N. Spatial and temporal structure of shear layer turbulence at a stream confluence. Water Resources Research, v. 40, W06304. DOI: 10.1029/2003WR002811, 2004.

RHOADS, B. L.; SUKHODOLOV, A. N. 2001. Field investigation of three-dimensional flow structure at stream confluences: 1 Thermal mixing and time-averaged velocities. Water Resources Research, v. 37, p. 2393-2410, 2001.

RHOADS, B. L.; KENWORTHY, S. T. Time-averaged flow structure in the central region of a stream confluence. Earth Surface Processes and Landforms, v. 23, p. 171-191, 1998.

RHOADS, B. L. Mean structure of transport-effective flows at an asymmetrical confluence when the main stream is dominant. In: ASHWORTH, P. J.; BENNETT S. J.; BEST, J. L.; MCCLELLAND, S. J. Coherent Flow Structures in Open Channels. 1996. p. 491-517.

RHOADS, B. L.; KENWORTHY, S.T. Field measurements of flow structure at a high-angle asymmetrical stream confluence. Geomorphology, v. 11, p. 273-293, 1995.

RIBEIRO, M. L.; BLANCKAERT, K.; ROY, A. G.; SCHLEISS, A. J. Flow and sediment dynamics in channel confluences. Journal of Geophysical Research, v. 117, F01035, doi:10.1029/2011JF002171, 2012.

RICE, S. P.; ROY, A. G.; RHOADS, B. L. River confluences, tributaries and the fluvial network. Chichester, United Kingdom: John Wiley and Sons, 2008a. 484 p.

RICE, S. P.; KIFFNEY, P.; GREENE, C.; PESS, G. R. The ecological important of tributaries and confluences. In: RICE, S. P.; ROY, A. G.; RHOADS, B. L. River confluences, tributaries and the fluvial network. v. 1, 2008b. cap. 11, p. 209-242.

RICE, S. P.; FERGUSON, R. I.; HOEY, T. Tributary control of physical heterogeneity and biological diversity at river confluences. Canadian Journal of Fisheries and Aquatic Sciences, v. 63, p. 2553-2566, 2006. 
RICE, S. P.; GREENWOOD, M. T.; JOYCE, C. B. Tributaries, sediment sources and the longitudinal organisation of macroinvertebrate fauna along river systems. Canadian Journal of Fisheries and Aquatic Sciences, v. 58, p. 824-840, 2001.

RICHARDSON, W. R.; THORNE, C. R. Multiple thread flow and channel bifurcation in a braided river: Brahmaputra-Jamuna River, Bangladesh. Geomorphology, v. 38, p. 185-196, 2001.

ROBERTS, M. V. T. Flow dynamics at open channel confluent-meander bends. 2004. 156 f. Tese (Doutorado em Environnement) University of Leeds, Leeds - United Kingdom, 2004.

ROY, A. G.; BERGERON, N. Flow and particle paths at a natural river confluence with coarse bed material. Geomorphology, v. 3, p. 99-112, 1990.

ROY, A. G.; BERGERON, R. N. Hydraulic geometry and changes in flow velocity at a river confluence with coarse bed material. Earth Surface Processes and Landforms, v. 13, p. 5 83-598, 1988.

STEVAUX, J. C.; FRANCO, A. A.; ETCHEBEHERE, M. L. C.; FUJITA, R. H. Flow structure and dynamics in large tropical river confluence: Example of the Ivaí and Paraná Rivers, southern Brazil. Geociências, v. 28, p. 5-13, 2009 a.

STEVAuX, J. C.; PAES, R. J.; ETCHEBEHERE, M. L.;
FRANCO, A. A.; FUJITA, R. H. Morphodynamics in large regulated river confluence: The case of Paraná and Paranapanema Rivers. Latin American Journal of Sedimentology and Basin Analysis, v. 16, n. 2, p. 23-35, 2009 b.

SUKHODOLOV, A. N.; RHOADS, B. L. Field investigation of three-dimensional flow structure at stream confluences: 2 Turbulence. Water Resources Research, v. 37, p. 2411-2424, 2001.

TURRA, T. M.; MARQUES, V. V; STEVAUX, J. C. Confluence bar of the São Pedro Brook in the Paraná River: Genesis and environmental importance. Boletim Goiâno de Geografia, v. 19, n. 1, p. 50-54, 1999.

WEBER, L. J.; SCHUMATE, E. D.; MAWER, N. Experiments on flow at a $90^{\circ}$ open-channel junction. Journal of Hydraulic Engineering, v. 127, p. 340-350, 2001.

WEERAKOON, S. B.; KAWAHARA, Y.; TAMAI, N. Three dimensional flow structure in channel confluence of rectangular section. In: PROCEEDINGS OF THE 25TH INTERNATIONAL ASSOCIATION FOR HYDRAULIC RESEARCH CONGRESS, 25., 1991, Madrid. Anais... Madrid: International Association for Hydraulic Research, 1991, p. 373-380.

VAN DEN BERGER, J. H. Prediction of alluvial channel pattern of perennial rivers. Geomorphology, v. 12, n. 4, p. 259-279, 1995. 